\title{
ERP SYSTEM
}

\author{
By: \\ AMAN KUMAR DAS \\ JYOTI RANJAN MOHAPATRA \\ NIKHIL RANJAN NAYAK \\ MUDDANA ADITYA
}

December $26^{\text {th }}, 2019$

DEPARTMENT OF COMPUTER SCIENCE AND ENGINEERING Institute of Technical Education and Research SIKSHA 'O’ ANUSANDHAN UNIVERSITY

Bhubaneswar, Odisha, India 


\section{ACKNOWLEDGEMENT}

It is matter of great pleasure for us to get this opportunity expressing our sincere sense of gratitude to Siksha "O" Anusandhan Deemed to be University. Firstly, we would like to express our heartily thanks to Institute of Technical Education and Research for providing lab facility and other relevant facilities. My guide Ms. Binita Kumari was the main force behind all these efforts. Because of her/his valuable suggestions and proper guidance for this project. We express our sincere thanks to the Computer Science \& Engineering department HOD Prof (Dr.) Debahuti Mishra who had allowed us to use facilities of the institute. We are also thankful to all those who have helped us in this endeavour either directly or indirectly especially all our teachers. At last we would like to express a big thank you to all friends and all known \& unknown person who had helped us directly or indirectly. 


\section{CERTIFICATE}

This is to certify that the project report titled "ERP SYSTEM" being submitted by AMAN KUMAR DAS，JYOTI RANJAN MOHAPATRA，NIKHIL RANJAN NAYAK，MUDDANA ADITYA of CSE section ' $F$ ' to the institute of Technical Research and Education, Siksha 'O' Anusandhan University, Bhubaneswar for the partial fulfillment for the degree of Bachelor of Technology in Computer Science and Engineering is a record of Original confide work carried out by them under my/our supervision and guidance. The project work, in my/our opinion, has reached the requisite standard fulfilling the requirements for the degree of Bachelor of Technology. The application developed for this project work have not been submitted in part or full to any other University or Institute for the award of any degree or diploma.

\section{Ms. Binita Kumari}

\section{Computer Science \& Engineering}

ITER, SOA Deemed to be University 


\section{DECLARATION}

We declare that this written submission represents our ideas in our own words and where other's ideas or words have been included, we have adequately cited and referenced the original sources. We also declare that we have adhered to all principles of academic honesty and integrity and have not misrepresented or fabricated or falsified any idea/fact/source in our submission. We understand that any violation of the above will be cause for disciplinary action by the University and can also evoke penal action from the sources which have thus not been properly cited or from whom proper permission has not been taken when needed. 


\section{CONTENTS}

Project Abstract

1. Introduction

1.1 Purpose

1.2 Scope

1.3 Objective

2. Feasibility study

2.1 Technical feasibility

2.2 Implementation feasibility

2.3 Operational feasibility

2.4 Economical feasibility

3. Requirement study

3.1 Hardware requirements

3.2 Software requirements

4. System Analysis

4.1 Study of the current System

4.2 Problems and weakness of the current system

4.3 Requirement of new system

5. UML diagrams

5.1 Use case diagram

5.2 Class diagram

5.3 State diagram

5.4 Sequence Diagram

6. Screenshots

6.1 Login page

6.2 Menu page

6.3 Customer page

6.4 Employee page

6.5 Site page

6.6 Add Expense

6.7 Attendance

6.8 Inventory 
7. Testing

7.1 White Box Testing

7.2 Black Box Testing

7.3 Unit Testing

7.4 Integration Testing

8. Limitations and Future Enhancements

8.1 Limitations

8.2 Future Enhancements

9. Conclusion

10. References 


\section{Project Abstract}

The main objective behind the ERP (Enterprise resource planning) is creating a central system while in traditional approach is to do a manual work in paper. So, for that it's very difficult to manage all the record and also difficult to analyze all the record in any departments. A manual work is to lengthy and its very time consuming for the entire department. So, for that needs of central system are arising which gives the effective and efficient result within a few times. All departments can access the data with the system and also, they can perform a desire task. With that all the data can easily manipulate and get easily whenever anybody wants.

\section{Introduction}

\subsection{Purpose}

The project is about to handle all the information of the employees regarding orders and inventories. Also, it manages resources which were managed and handled by manpower previously. The main purpose of the project is to integrate distinct sections of the organization into consistent manner so that complex functions can be handled smoothly by any technical or non-technical persons.

The project aims at the following matters:

- To manage information of employee data, inventories and orders.

- Consistently update information of all the employees.

- Assistance in decision-making.

\subsection{Scope}

- Different people, place from different departments can view the same information about Employee Information.

- To enable the head and technical supporting group to access the system from anywhere.

- To enable the employee to view as well as raise suggestion from anywhere.

\subsection{Objective}

- Manage the all the record of the employee

- Manage the all the record of the Inventories

- Site management along with expense tracker and view transactions

- Manage all the records of the customers 


\section{Feasibility Study}

The aim of the feasibility study activity is to determine whether it would be financially and technically feasible to develop the system or not. A feasibility study is carried out from following different aspects:

\subsubsection{Technical Feasibility}

Technical feasibility corresponds to determination of whether it is technically feasible to develop the software. It refers to the ability of the process to take advantage of the current state of the technology in pursuing further improvement. The technical capability of the available technology should be considered.

- The following technical feasibility areas were probed during the feasibility study phase:

The necessary technology i.e. front-end development tools, back-end database technology for developing the system are already available within the organization.

- The front-end tool proposed in easily compatible with the current hardware configuration in the organization.

- The back-end tool proposed has the capacity to hold the data required for using the new system.

- The System is expandable in many dimensions with respect to addition of more functionality, featured, etc.

- The front-end and back-end technologies provide a way to preserve the accuracy, reliability and ease of access and data security.

\subsubsection{Implementation Feasibility}

This project can easily be made available online without much consideration of the hardware and software. The only required thing at the applicant's side is the Internet connection and a web browser, which are a no difficult issue these days. A database server and application server are required to set up at the admin side. After setting up the project online, even the administrator can access the system from anywhere.

\subsubsection{Operational Feasibility}

The system has been developed for any user who wants to use this system. we have given a demo of our project and the users found the system friendly and easy to use. The interoperability with the existing system is also checked. So, they may face certain problems in using the user interface. So, keeping this consideration in mind we have provided field for each and every field on the forms. The 
administrator also may be non-technical, so the user interface is designed in such a way that it gets comfortable for the non-technical person to operate easily

\subsubsection{Economical Feasibility}

The company being a well-to-do company didn't have any problem in buying any software that was required in developing the application. The software's we used were readily available. So as such we didn't face any economical constrains.

\section{Requirement Study}

\subsection{Hardware Requirements}

Since neither the web application nor the web portal have any designated hardware, it does not have any direct hardware interfaces. The hardware connection to the database server is managed by the underlying operating system on the device and the web server. This website can be accessed by any device which has network connectivity with a browser and display such as mobile phones, tablets and PCs with a minimum of 256 MB RAM.

\subsection{Software Requirements}

The use of other required software products and interfaces with other application systems include PHP, HTML 5, CSS 3. jQuery 1.1.2, JavaScript and Bootstrap for smooth and sound rum of website. Browsers such as World Wide Web, Mosaic, Netscape Navigator, Netscape Communicator, Internet Explorer, Opera, Mozilla Navigator, Safari, Mozilla Firefox, Google Chrome, Microsoft Edge and UC Browser can be used to access the website.

\section{System Analysis}

\subsection{Study of the Current System}

The current ERP System deals with maintaining a physical contact with the management for filling all the details and the documentation work.

According to the current system, the management has to fill in the forms manually, go to the account management dept., and submit the form. The applicant needs to visit the portal now and then in order to get his work accomplished. The admin also has to manage all the users. He needs to maintain records of all the users, their activity status, submission methods and installation details on paper. The 
Manual process is more error prone and also slow. Thus, a simulation of this entire process can be a boon to the applicants as well as the admin.

\subsection{Problems and Weakness of Current System}

- The present system has certain major disadvantages. A few to be listed can be excessive paperwork, time consuming process flow, laborious work environment for employees, difficulty to access historical data and all these problems lead to inefficient working of government sector causing dissatisfaction in the general public.

- Apart from the above stated problems there is lack of transparency in the existing system. This being one of the major drawbacks in the system needs special attention.

- The problem stated above have certain deep-rooted problems like time consuming process flow for which may need to change the structure of the process flow in certain cases so that the system output can become faster.

- So much time consume in preparing registers which is having replicated data

\subsection{Requirement of New System}

- Information of all the members of the applicant's group.

- All information and rules regarding the e-forms must follow.

- Communication with whole system.

- To automate selection process for the company.

- Facilitating high graphical user interface to the user.

- Providing attendance management system for the employees.

- Showing an updated chart of the company's monthly, quarterly and annual profit and loss. 


\section{UML Diagrams}

\subsection{Use Case Diagram}

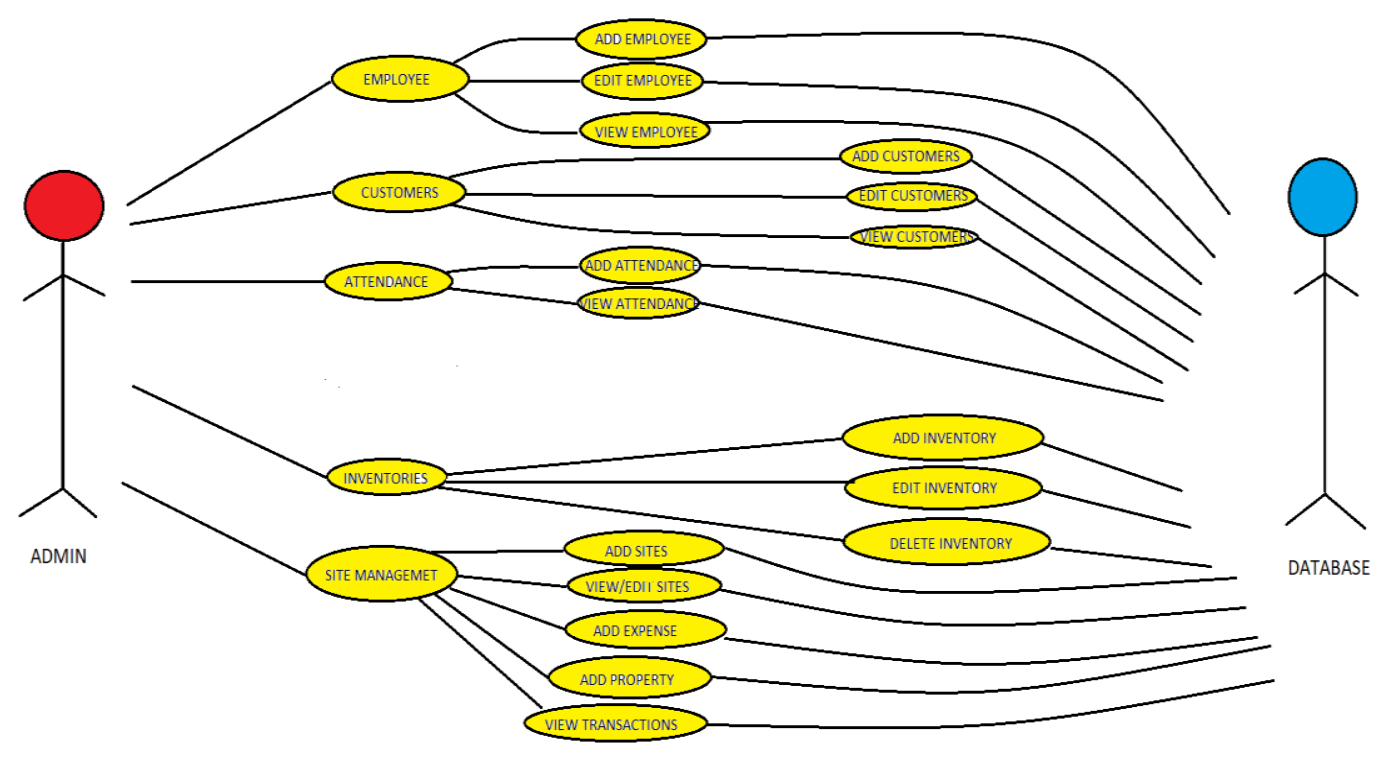




\subsection{Class Diagram}

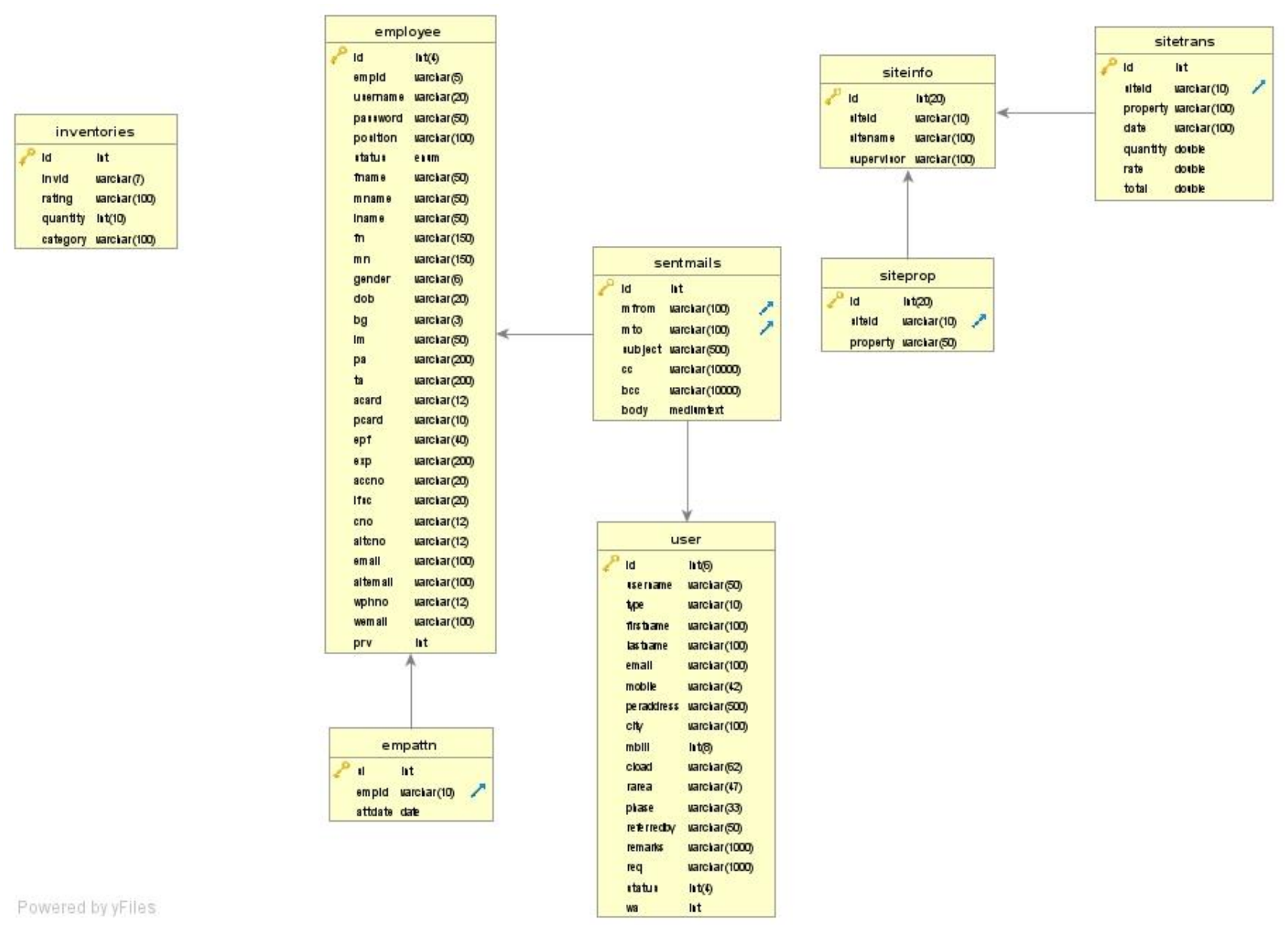




\subsection{State Diagram}

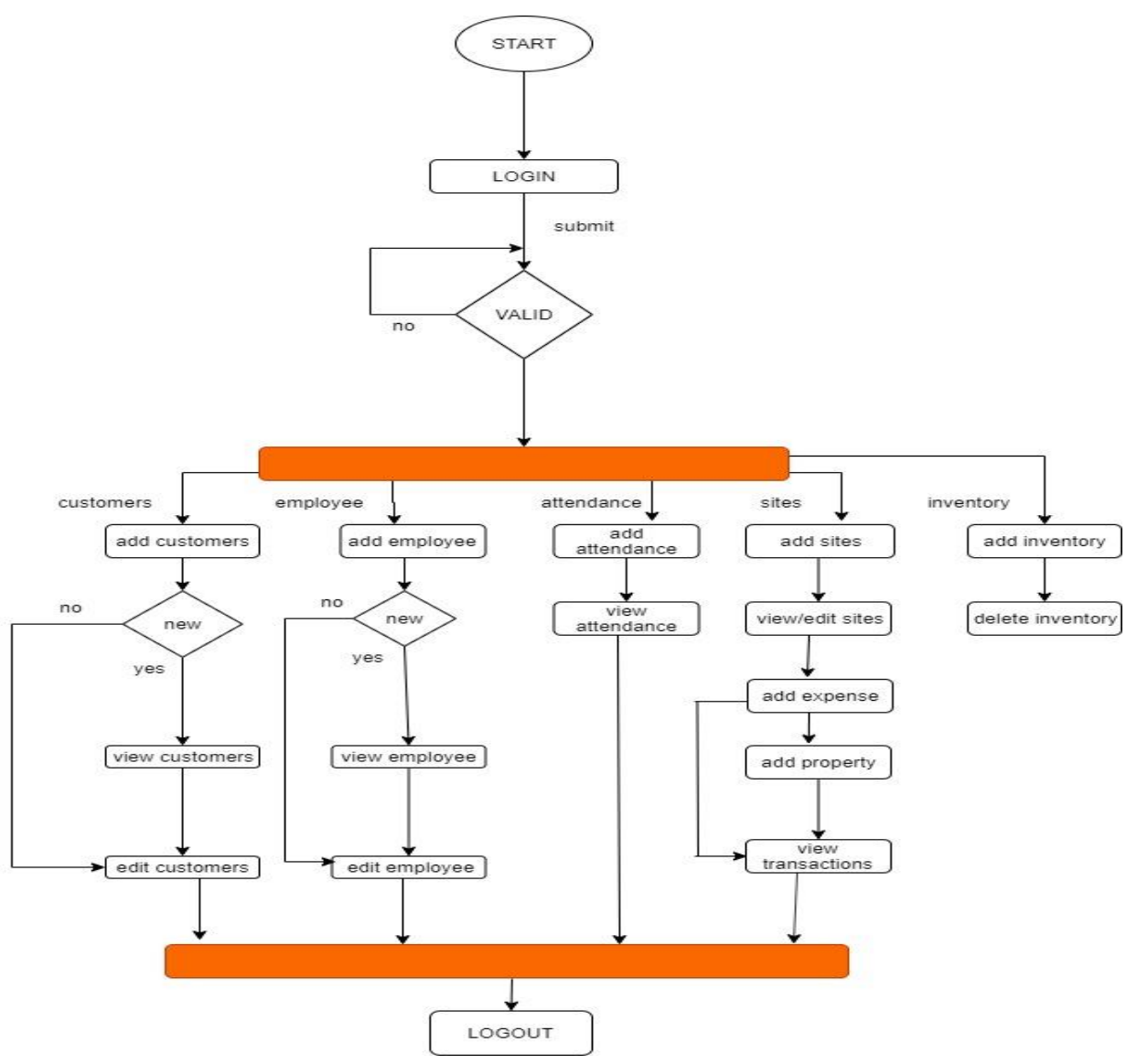

\subsection{Sequence Diagram}

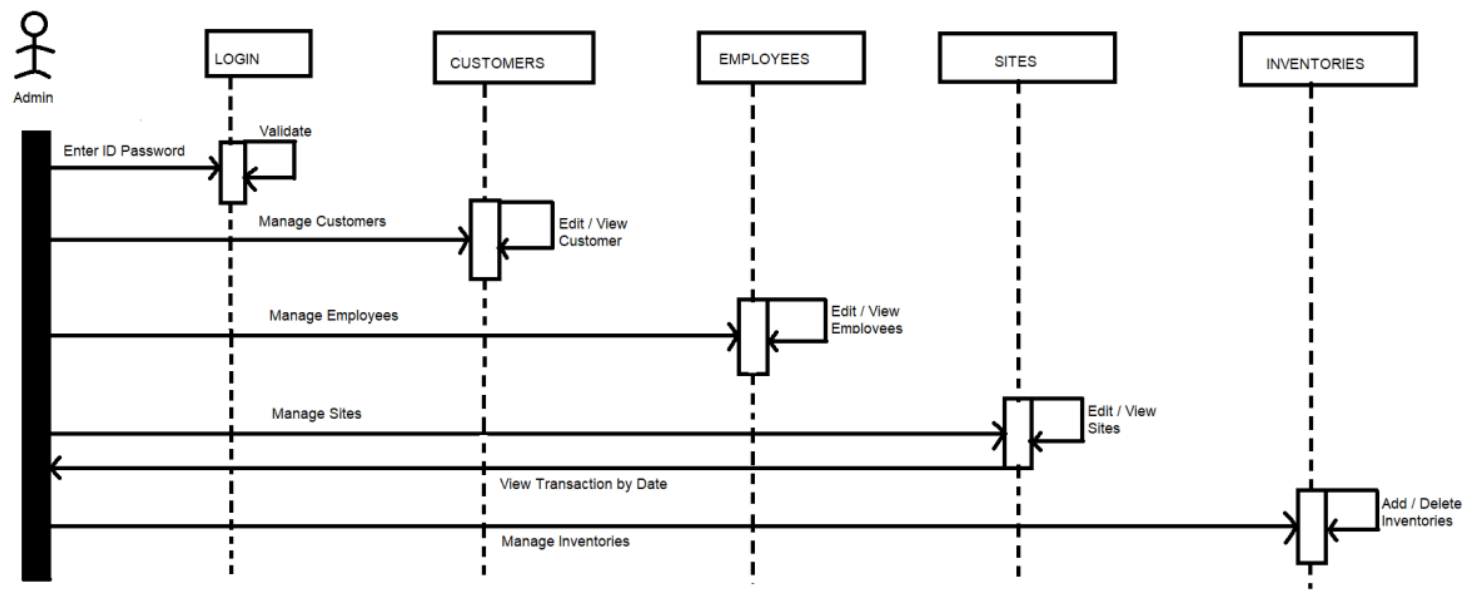


6. Screenshots

6.1 Login

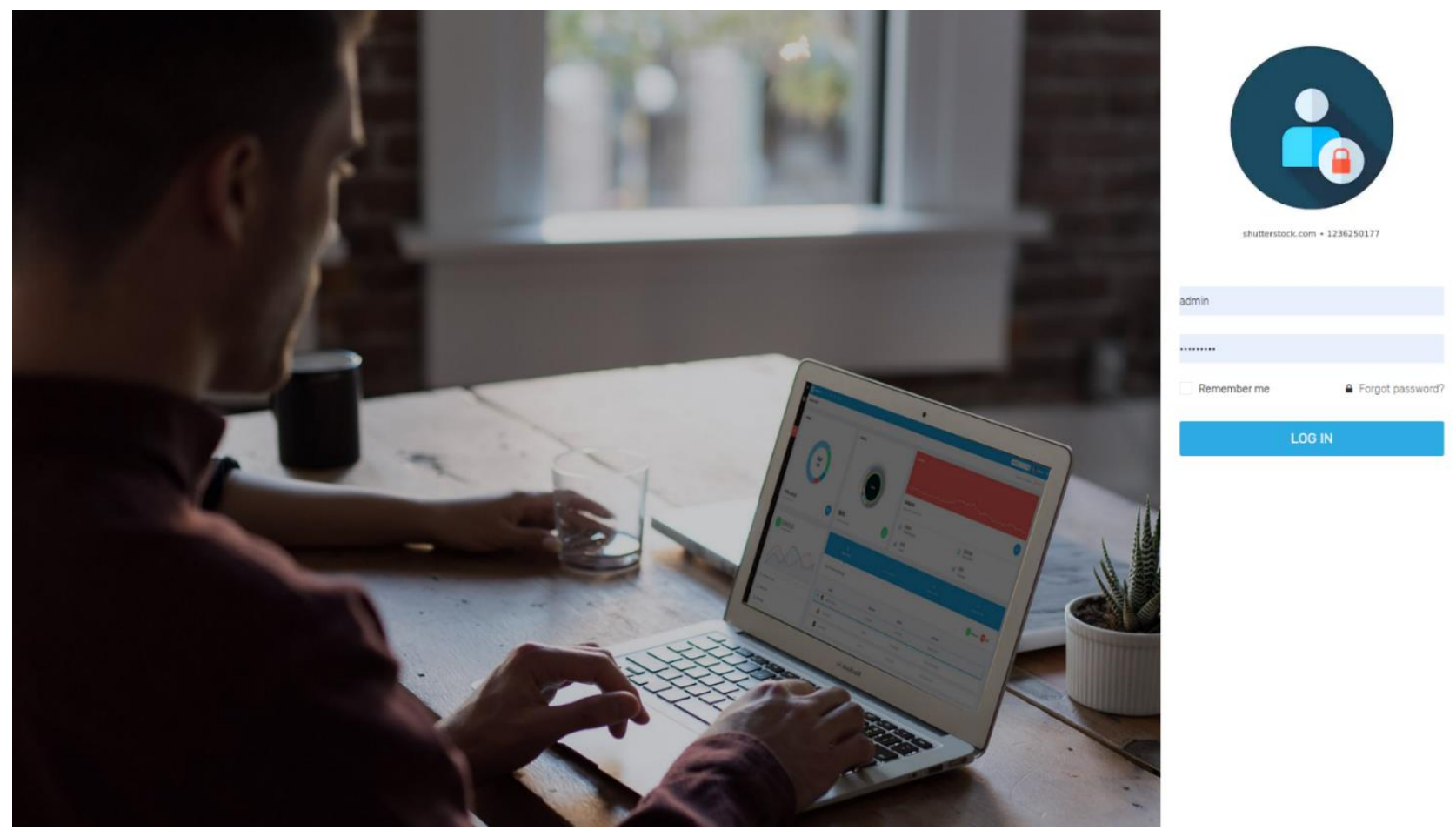




\subsection{Menu Page}

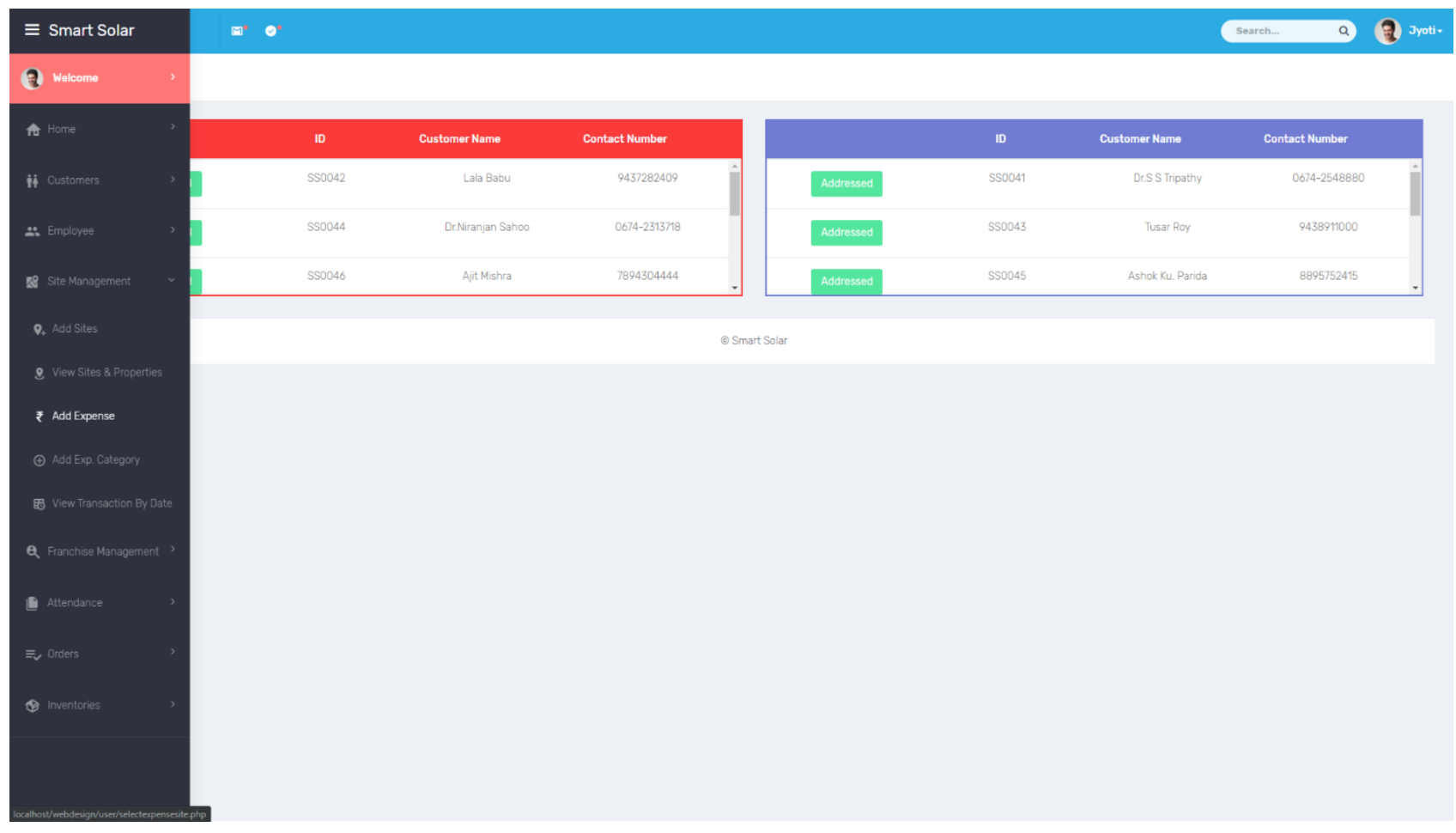




\subsection{Customer Page}

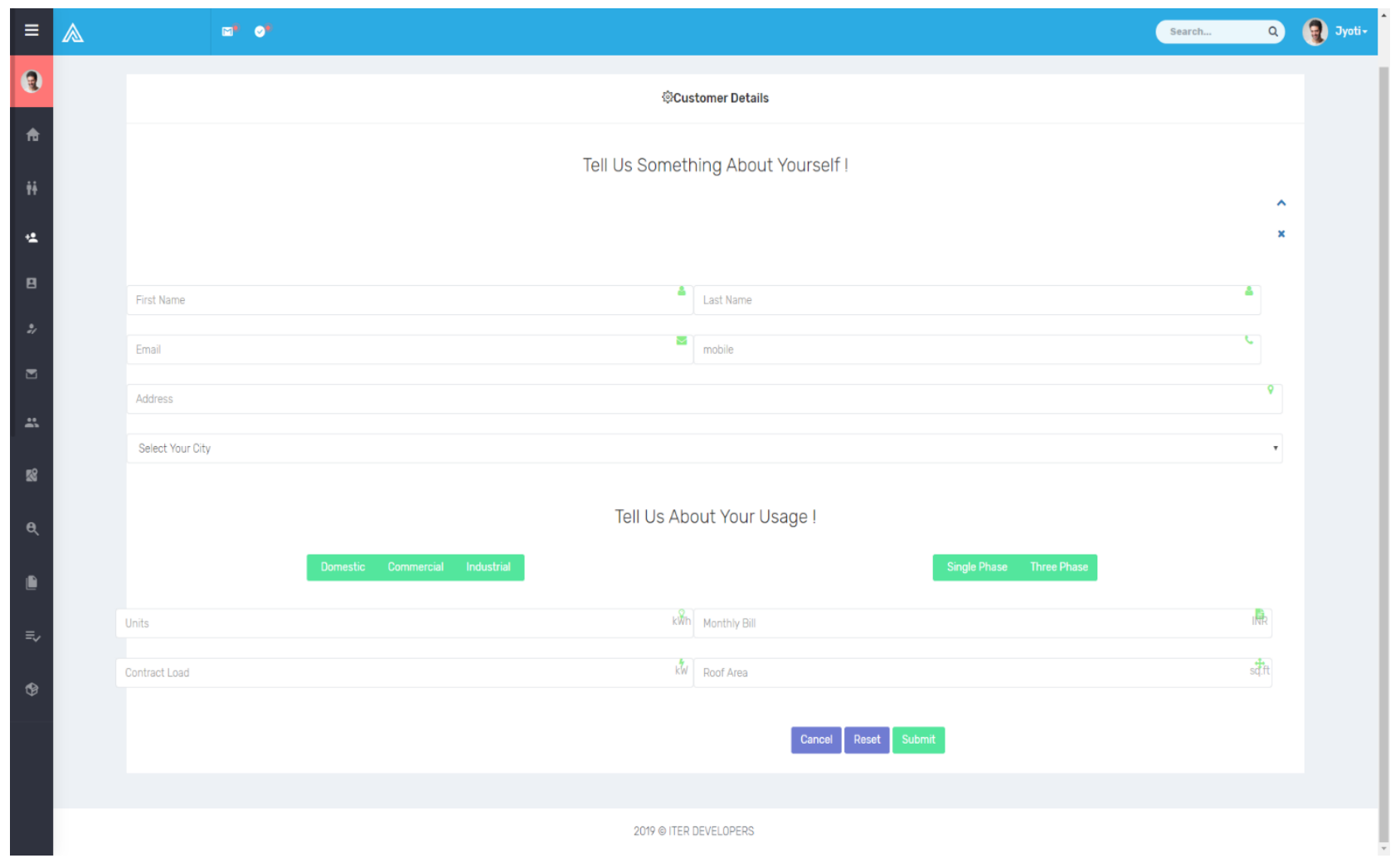




\subsection{Employee Page}

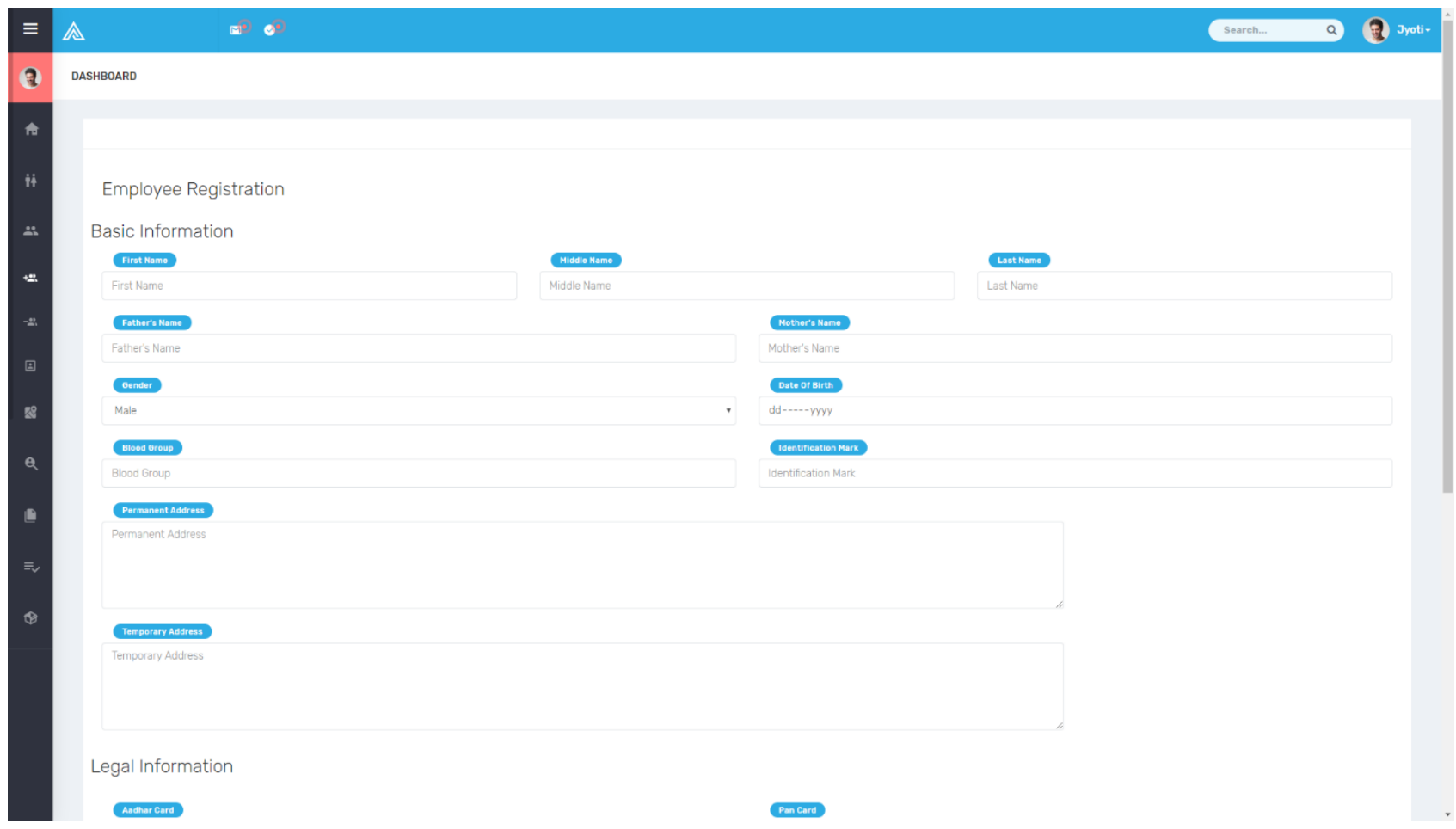


6.5 Site Page

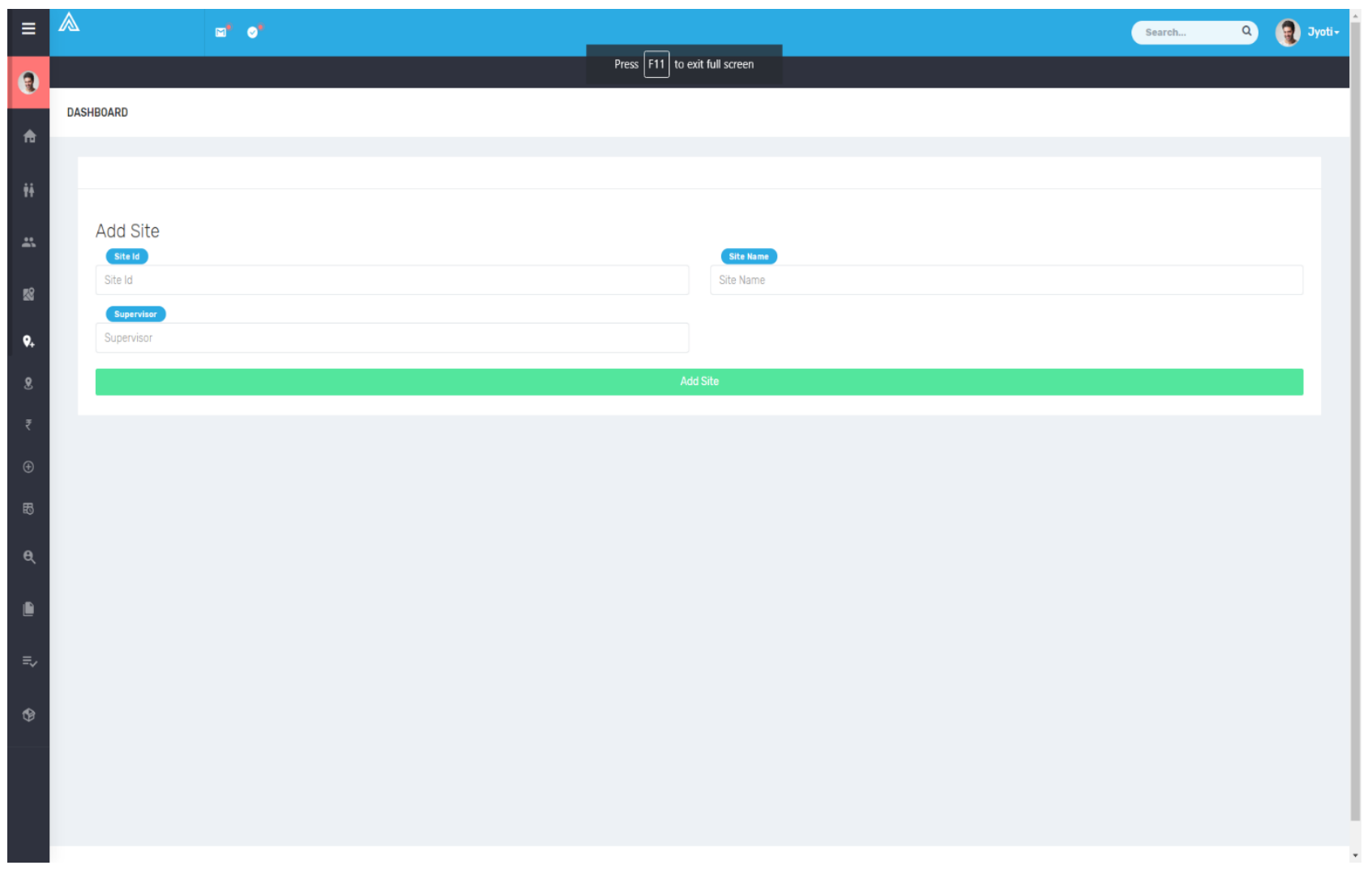




\subsection{Add Expense}

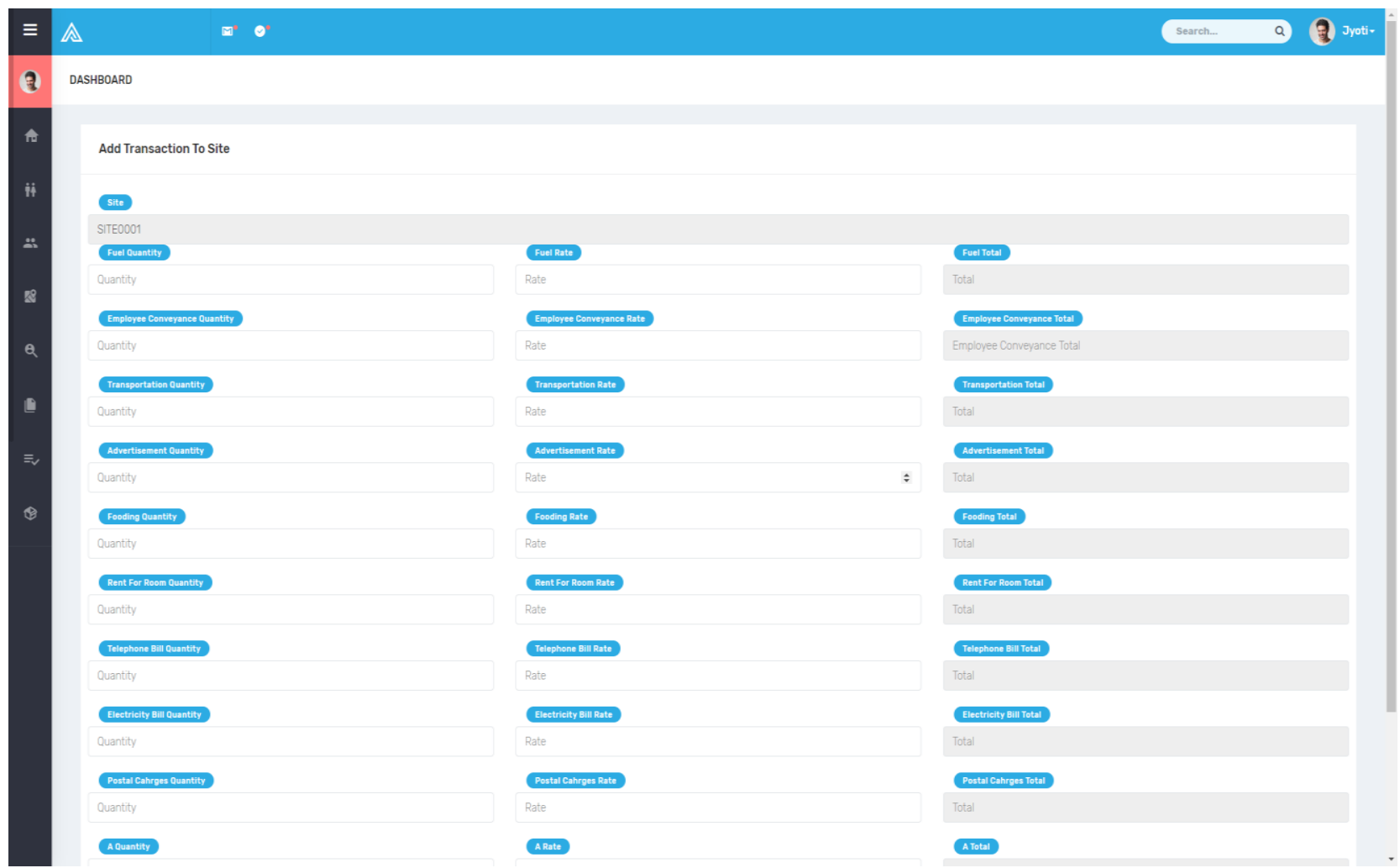




\subsection{Attendance}

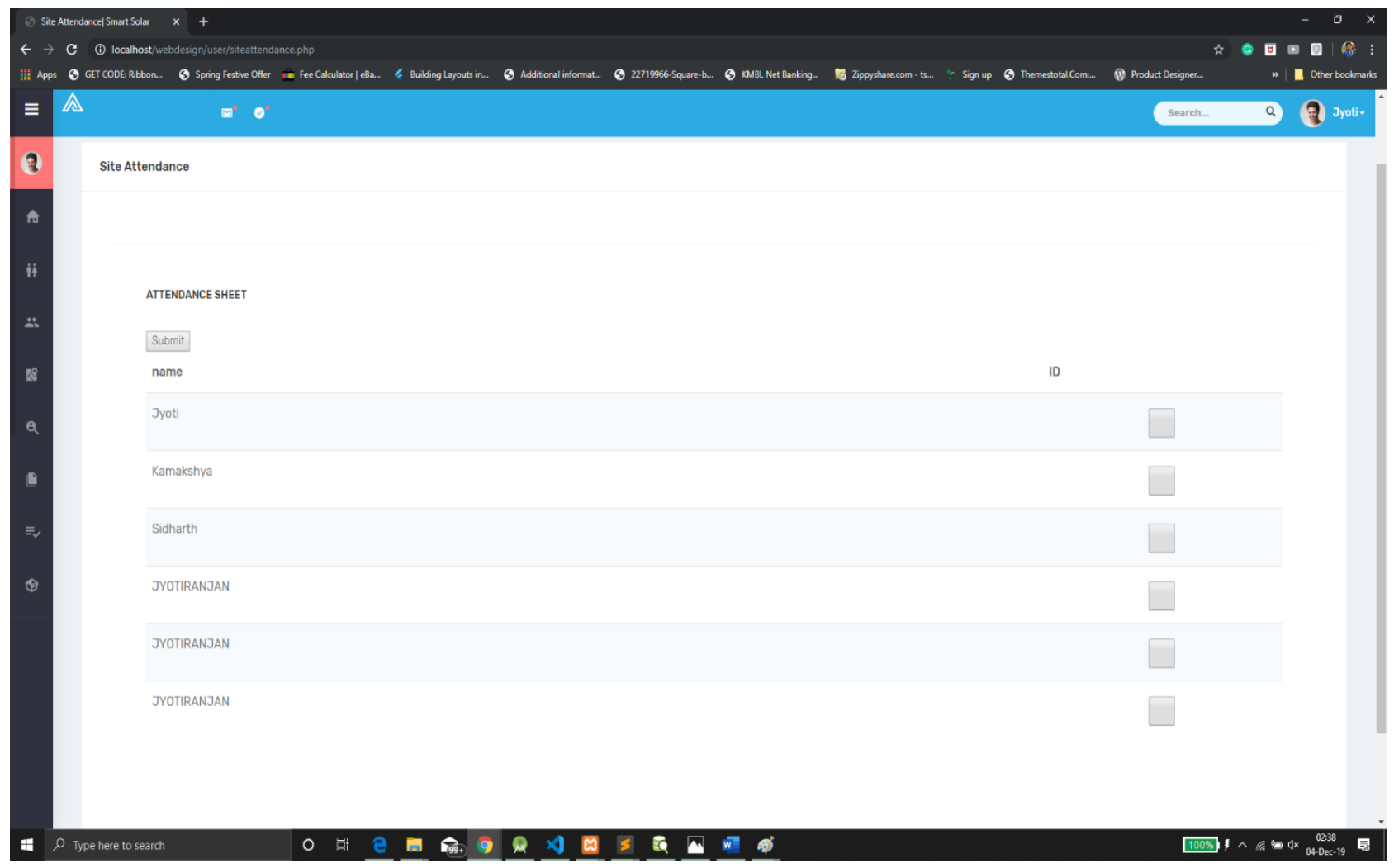




\subsection{Inventory}

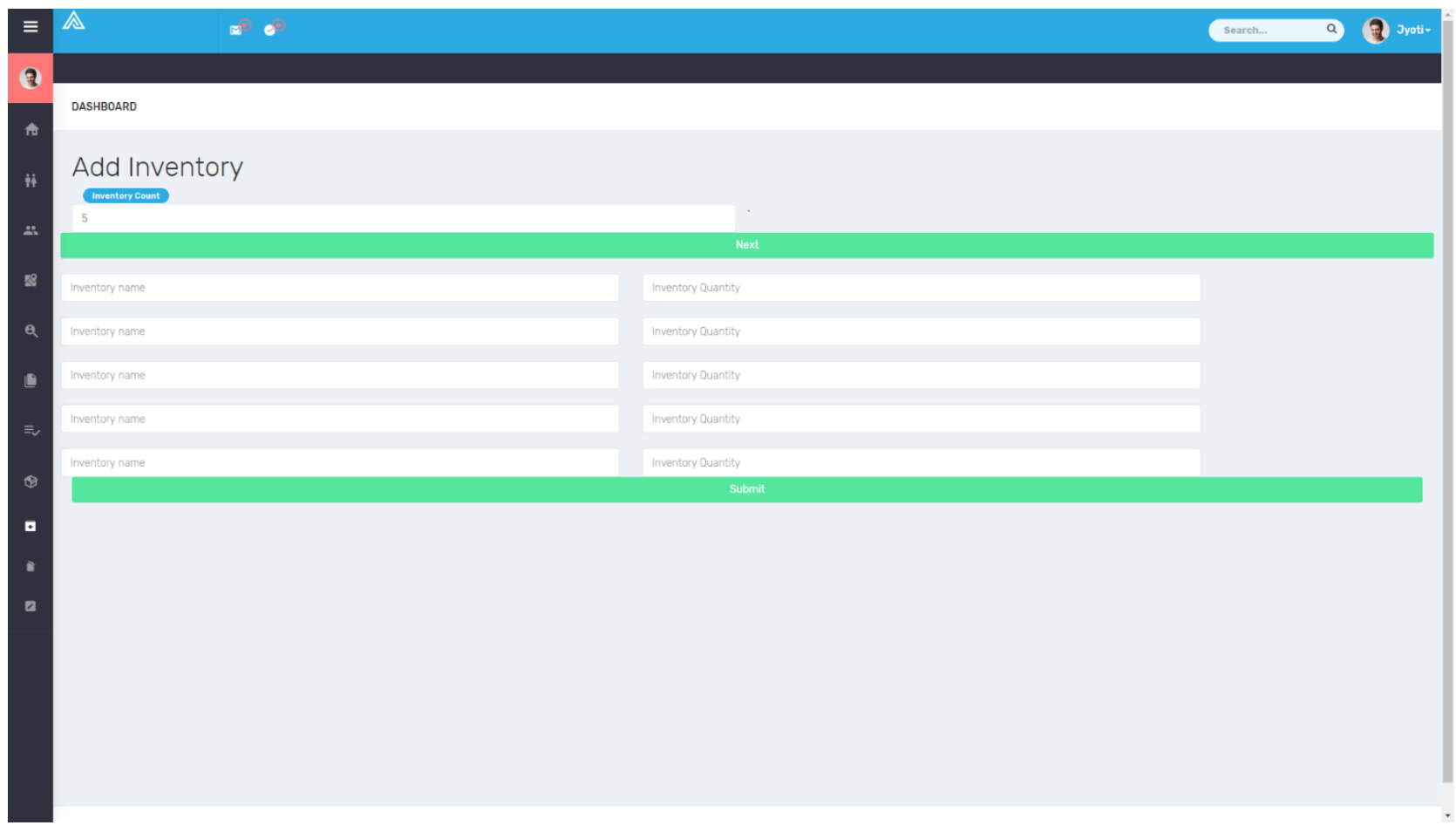




\section{Testing}

Software Testing has a dual function; it is used to identify the defects in program and it is used to help judge whether or not program is usable in practice. Thus, software testing is used for validation and verification, which ensure that software conforms to its specification and meets need of the software customer.

\subsection{White Box Testing}

White-box testing (also known as clear box testing, glass box testing, transparent box testing, and structural testing) is a method of testing software that tests internal structures or workings of an application, as opposed to its functionality (i.e. black-box testing). In white-box testing an internal perspective of the system, as well as programming skills, are used to design test cases. The tester chooses inputs to exercise paths through the code and determine the appropriate outputs.

\subsection{Black Box Testing}

Black-box testing is a method of software testing that examines the functionality of an application (e.g. what the software does) without peering into its internal structures or workings. This method of test can be applied to virtually every level of software testing: unit, integration, system and acceptance. It typically comprises most if not all higher-level testing, but can also dominate unit testing as well.

\subsection{Unit Testing}

In computer programming, unit testing is a software testing method by which individual units of source code, sets of one or more computer program modules together with associated control data, usage procedures, and operating procedures are tested to determine if they are fit for use. Intuitively, one can view a unit as the smallest testable part of an application. In procedural programming, a unit could be an entire module, but it is more commonly an individual function or procedure. In objectoriented programming, a unit is often an entire interface, such as a class, but could be an individual method. Unit tests are short code fragments created by programmers or occasionally by white box testers during the development process.

\subsection{Integration Testing}

Integration testing (sometimes called integration and testing, abbreviated I\&T) is the phase in software testing in which individual software modules are combined and tested as a group. It occurs after unit testing and before validation testing. Integration testing takes as its input modules that have been unit 
tested, groups them in larger aggregates, applies tests defined in an integration test plan to those aggregates, and delivers as its output the integrated system ready for system testing.

\subsection{Validation Testing}

Validations are independent procedures that are used together for checking that a product, service, or system meets requirements and specifications and that it fulfils its intended purpose. The words "verification" and "validation" are sometimes preceded with "Independent" (or IV\&V), indicating that the verification and validation is to be performed by a disinterested third party.

\section{Limitations \& Future Enhancements}

\subsection{Limitations}

Storage capacity too small so that it cannot be stored large amount of data so take back up is necessary for the future requirement. So limited amount of data can be stored.

\subsection{Future Enhancements}

It has been marking while this application open in other browser due to designing support. It has more support in Chrome as compare to other browsers.

Need to improve more security for the purpose of the safety.

\section{Conclusion}

No project can be termed as 'perfect' in real sense and there always remains scope for future improvement and so that helps to develop a new version of the software. We are always eager to know some new points and validation related to projects which give us more knowledge and help us to create new version.

The "ERP" system has been developed by us and also done enhancement in application through applying our knowledge gained in class room, referring to certain books, browsing some sites and through the help of external and internal faculties and using our knowledge related to subject it. We are very thankful to the project guide and college staffs that extended all their support and helped us complete this project successfully. 


\section{Reference}

\section{WEBSITES}

- http://books.google.com/

- http://www.thefreecountry.com/

- http://www.gnu.org/

\section{BOOKS}

- PHP Specification- By: Rajiv Mordani

- PHP and MYSQL - By: Marty Hall, Larry Brown, Yaakov Chaikin 